\title{
Materials research for fusion
}

\author{
J. Knaster ${ }^{1 \star}$, A. Moeslang ${ }^{2}$ and T. Muroga ${ }^{3}$
}

Fusion materials research started in the early 1970s following the observation of the degradation of irradiated materials used in the first commercial fission reactors. The technological challenges of fusion energy are intimately linked with the availability of suitable materials capable of reliably withstanding the extremely severe operational conditions of fusion reactors. Although fission and fusion materials exhibit common features, fusion materials research is broader. The harder mono-energetic spectrum associated with the deuterium-tritium fusion neutrons (14.1 MeV compared to $<2 \mathrm{MeV}$ on average for fission neutrons) releases significant amounts of hydrogen and helium as transmutation products that might lead to a (at present undetermined) degradation of structural materials after a few years of operation. Overcoming the historical lack of a fusion-relevant neutron source for materials testing is an essential pending step in fusion roadmaps. Structural materials development, together with research on functional materials capable of sustaining unprecedented power densities during plasma operation in a fusion reactor, have been the subject of decades of worldwide research efforts underpinning the present maturity of the fusion materials research programme.

S ince Isaac Newton unravelled gravitation in the 17th century, the source of the Sun's light was attributed to the conversion of gravitational energy into heat as the Sun steadily contracts. However, William Thompson's estimations in 1862 predicted a life for the Sun not longer than 30 million years, in contrast with the geological and evolutionary models existing at the beginning of 20th century. In 1920, Arthur Eddington suggested the possibility that the stars are crucibles where hydrogen nuclei fuse together, with a release of energy given by Albert Einstein's celebrated 1905 formula: 'We sometimes dream that man will learn one day how to release it and use it for his service. The store is well-nigh inexhaustible, if only it could be tapped"1. Our generation is lucky to witness, and partake in, the second attempt of humans to control fire-this time the fire from the heart of the stars. However, the requirement of confining a stable plasma under the right ignition conditions regarding time, temperature and density, as defined by John David Lawson's 1957 triple product ${ }^{2}$, continues to be a difficult challenge.

Nuclear fusion materials research started in the early 1970s, one decade after the first commercial fission reactors started operation. For a fusion reactor, strict safety standards are required for the thermomechanical properties of the in-vessel components that are exposed to severe irradiation and heat fluxes; they are also an essential requirement for the economic viability of fusion. Furthermore, not only the radiation hardness of components has a strong impact on the long-term operation of a plant, but also the operating temperature of the materials involved determines the thermodynamic efficiency of power plants of the future.

Today, the nuclear fusion of a deuteron $\left({ }^{2} \mathrm{H}\right)$ and a triton $\left({ }^{3} \mathrm{H}\right)$ is considered to be the most promising reaction for a commercial fusion power plant: ${ }^{2} \mathrm{H}+{ }^{3} \mathrm{H} \rightarrow{ }^{3} \mathrm{He}(3.5 \mathrm{MeV})+n(14.1 \mathrm{MeV})$. To overcome the Coulomb repulsion between the deuteron and the triton, plasma temperatures of about $20 \mathrm{keV}\left(\sim 2 \times 10^{8} \mathrm{~K}\right)$ are required, a challenge not only for plasma physicists but also for materials scientists dealing with plasma-wall interactions and the lifetime of plasma-near in-vessel components. Energy from fusion power will be extracted from the $14.1 \mathrm{MeV}$ kinetic energy of the neutrons produced in deuterium-tritium fusion reactions. Thus, this kinetic energy should be absorbed, efficiently channelled and eventually used for the generation of electricity by the conventional scheme of a thermal power plant.

\section{Primary neutron irradiation damage}

Neutrons have about the same mass as protons; however, unlike protons, they can strongly interact with atoms at very low energies (their charge neutrality implies that no Coulomb barrier has to be overcome). Degradation of materials under neutron irradiation was already anticipated in 1946 by Eugene Wigner, who argued theoretically that neutrons could displace atoms through irradiation: 'The matter has great scientific interest because pile irradiations should permit the artificial formation of displacements in definite numbers and a study of the effect of these on thermal and electrical conductivity, tensile strength, ductility, etc., as demanded by the theory'3.

The integration of the flux in a certain period of time-the fluence-and the absorbed dose are typically the two parameters used to characterize the exposure of a given material to irradiation, irrespective of the nature of the irradiated material. However, the number of factors that play a primary role in the eventual damage of a material exposed to a particular irradiation makes this description incomplete.

Under neutron irradiation, in the first stage after collision, a primary knock-on atom (PKA) is generated: the primary atom that recoils after being impacted by the neutron. This initial interaction can be both elastic and inelastic. In the latter case, some of the neutron's energy is transferred to a specific excited state of the collided atom, leaving the neutron and the recoiling primary atom with substantially less kinetic energy. Figure 1 illustrates the pathways of irradiation damage. Following the first impact, if no excited state is generated, the PKA recoils quasi-elastically and dissipates its initial kinetic energy by exciting the electrons of the medium and by elastic collisions with surrounding atoms of the impacted material. The total kinetic energy of the atoms involved in the recoiling is nearly conserved; the sum of the energies of the colliding and the collided secondary atom after scattering is 


\section{Box 1 | The International Fusion Materials Irradiation Facility (IFMIF).}

Neutrons with suitable fluxes and spectra for fusion materials testing, generated through $\operatorname{Li}(d, x n)$ nuclear reactions, are expected to be available by the middle of the next decade as stipulated in world fusion roadmaps. The successful accomplishment of the mandates of the Engineering Validation and Engineering Design Activities (EVEDA) phase of the International Fusion Materials Irradiation Facility (IFMIF) in Rokkasho, Japan, is gradually overcoming historical technological difficulties ${ }^{123}$. EVEDA is the combination of the Engineering Design Activities (EDA) phase, with the design of the plant accomplished in $2013^{118}$, backed by the experience gained in former phases ${ }^{124}$ and projects based on the same concept (FMIT, the Fusion Materials Irradiation Test facility ${ }^{125}$ in the US, and ESNIT, the Energy Selective Neutron Irradiation Test Facility ${ }^{126}$ in Japan), and the construction of prototypes in the parallel Engineering Validation Activities (EVA) phase ${ }^{114}$. The IFMIF/EVEDA project is part of the Broader Approach agreement between the Government of Japan and EURATOM on fusion energy research ${ }^{81}$.

IFMIF consists of two $125 \mathrm{~mA} 40 \mathrm{MeV}$ deuteron linear accelerators operating in continuous-wave $(\mathrm{CW})$ mode, that is, $100 \%$ duty cycle, each with a $200 \mathrm{~mm} \times 50 \mathrm{~mm}$ beam crosssection impacting concurrently on a lithium jet of thickness $25 \pm 1 \mathrm{~mm}$ flowing at $15 \mathrm{~m} \mathrm{~s}^{-1}$ at $250^{\circ} \mathrm{C}$ (see Fig. 5). Neutrons present in the impacting $250 \mathrm{~mA}$ deuteron nuclei can be stripped off in the lithium to generate a neutron flux in the forward direction (typically with $40 \%$ of the original deuteron energy, and basically with the same transversal profile of the deuteron beam) capable of providing above $20 \mathrm{dpa}_{\text {NRT }}$ per year in a volume of $500 \mathrm{~cm}^{3}$. This volume will house around 1,000 testing specimens in 12 capsules independently cooled with He gas at selected target irradiation temperatures within $\pm 3 \%$ for each set of specimens (with two sets fitted in each capsule). Nowadays, accelerator technology is ready to achieve $125 \mathrm{~mA}$ deuteron beams in CW mode with high operational availabilities ${ }^{127}$ thanks to the success of LEDA, the Low Energy Demonstration Accelerator that in 1999 ran a proton beam of $100 \mathrm{~mA}$ in $\mathrm{CW}$ mode at $6.7 \mathrm{MeV}$ (ref. 128); to the electro-cyclotron resonance (ECR) ion sources, which have been successfully operating with $\mathrm{H}^{+}$since the early $1990 \mathrm{~s}^{129}$; and to the development of superconducting resonators for light hadrons and low- $\beta$ beams at the beginning of this century $^{130,131}$. This feasibility is being demonstrated with the Linear IFMIF Prototype Accelerator (LIPAc) under installation and commissioning in Rokkasho, Japan ${ }^{132,133}$. The LIPAc will run a $125 \mathrm{~mA} \mathrm{CW}$ mode beam of deuterons at $9 \mathrm{MeV}$ output energy of a superconducting cryomodule-the $40 \mathrm{MeV}$ output energy of IFMIF's accelerators will be obtained using three additional superconducting cryomodules ${ }^{118}$. Furthermore, the stable long-term flow of the lithium screen within specified conditions has been demonstrated in the EVEDA Lithium Test Loop (ELTL) in Oarai, Japan ${ }^{120,121,134}$, thanks to stable operation of the $15 \mathrm{~m} \mathrm{~s}^{-1}$ lithium flow at $250^{\circ} \mathrm{C}$ during 25 consecutive days with surface-wave amplitudes in the 25 -mm-thick jet within the specified $\pm 1 \mathrm{~mm}$ range ${ }^{122}$ (see Fig. 6). Last, but not least, the concept of the High-Flux Test Module (HFTM) has been validated in Karlsruhe (Germany) with the construction and successful testing of a full-scale prototype $e^{19,135,136}$. It is worth highlighting that, given the limited available irradiated volume, the testing specimens required are small (typically $\sim 25 \mathrm{~mm}$ long), which is the result of intense work throughout decades ${ }^{32,137-139}$; their shape has been defined during the EVEDA phase ${ }^{140-143}$. The validation activities, however, have been far more extensive than the brief description above may suggest-for an overview, see ref. 115.

The lower thermal power of a demonstration fusion reactor, if compared with the ones considered in the past, suggests a reduction of the required performance of a fusion-relevant neutron source during the next decade. Possibly, only one accelerator at $125 \mathrm{~mA}$ in CW mode will suffice. The ongoing success of the IFMIF/EVEDA phase; the known cost of the facility (reliable because of the construction of prototypes of the most challenging hardware), which is marginal compared with the cost of a fusion power plant, together with its paramount relevance for the continuation of the fusion programme has recently triggered interest in the construction of a simplified version of IFMIF ${ }^{123,144-146}$. basically the same as that of the incident PKA, give or take the relatively small individual electron excitation energies. Each PKA is capable of displacing a large number of secondary atoms, the number of which is determined by the combination of the total amount of energy available and the energy required to displace an atom $^{4-6}$. Thus, if the secondary atoms impacted by the PKA acquire enough kinetic energy to be displaced from their lattice sites, a cascade of successive collisions might take place, typically with a tree-structure shape; this scenario occurs in the materials exposed to fusion neutrons of $14.1 \mathrm{MeV}$.

In the case of inelastic reactions, a significant part of the neutron energy is transferred to the recoiling atom, which remains in an excited state. Typically, incident neutrons must have energies above a sharp threshold, thus both the neutron and the PKAexcited nucleus end up having a substantially lower kinetic energy. Neutron-induced transmutations are as important as displacement damage in determining the suitability of a given material for nuclear applications ${ }^{7}$. Nuclei are transmuted through nuclear interactions with the incident neutrons into stable or radioactive nuclei mainly through $(n, \gamma),(n, p),(n, n p)$ and $(n, \alpha)$ reactions. Transmutations also lead to stoichiometric changes. For example, pure tungstenat present considered as a plasma-facing material in some parts of demonstration fusion reactors (beyond ITER) - transmutes into a W-18Re-3Os alloy after irradiation at $50 \mathrm{dpa}_{\mathrm{NRT}}$ (the concept of 'displacement per atom', $\mathrm{dpa}_{\mathrm{NRT}}$, is explained below), that is, into a completely different material ${ }^{8,9}$, whereas transmutation-induced alloy modifications fortunately have only minor effects on steels ${ }^{10}$. Also, the transmuted elements themselves can be subject to further inelastic collisions. Hydrogen permeation through metals is high, but permeation by other gases is not. In addition, helium is not soluble in metals; therefore, generated $\alpha$-particles accumulate in the microstructure of the irradiated material ${ }^{11,12}$. Furthermore, other radiation effects can take place besides the ballistic scenario, such as PKA sputtering ${ }^{13}$ : unusual radiation-induced chemical reactions leading to the formation of 'hot atoms ${ }^{14}$ and even phase changes resulting from the different stoichiometry caused by transmuted elements. Accounting for all the different interactions that can take place is difficult, as the dynamics is very complicated-the damaged lattice interacts through complex many-body processes. Such thermodynamically unstable microstructures evolve swiftly into more stable configurations; in turn, the remaining defects tend to agglomerate into clusters that are strongly dependent on the temperature of the irradiated material and the defect concentration $^{15,16}$, often leading to a severe degradation of materials 


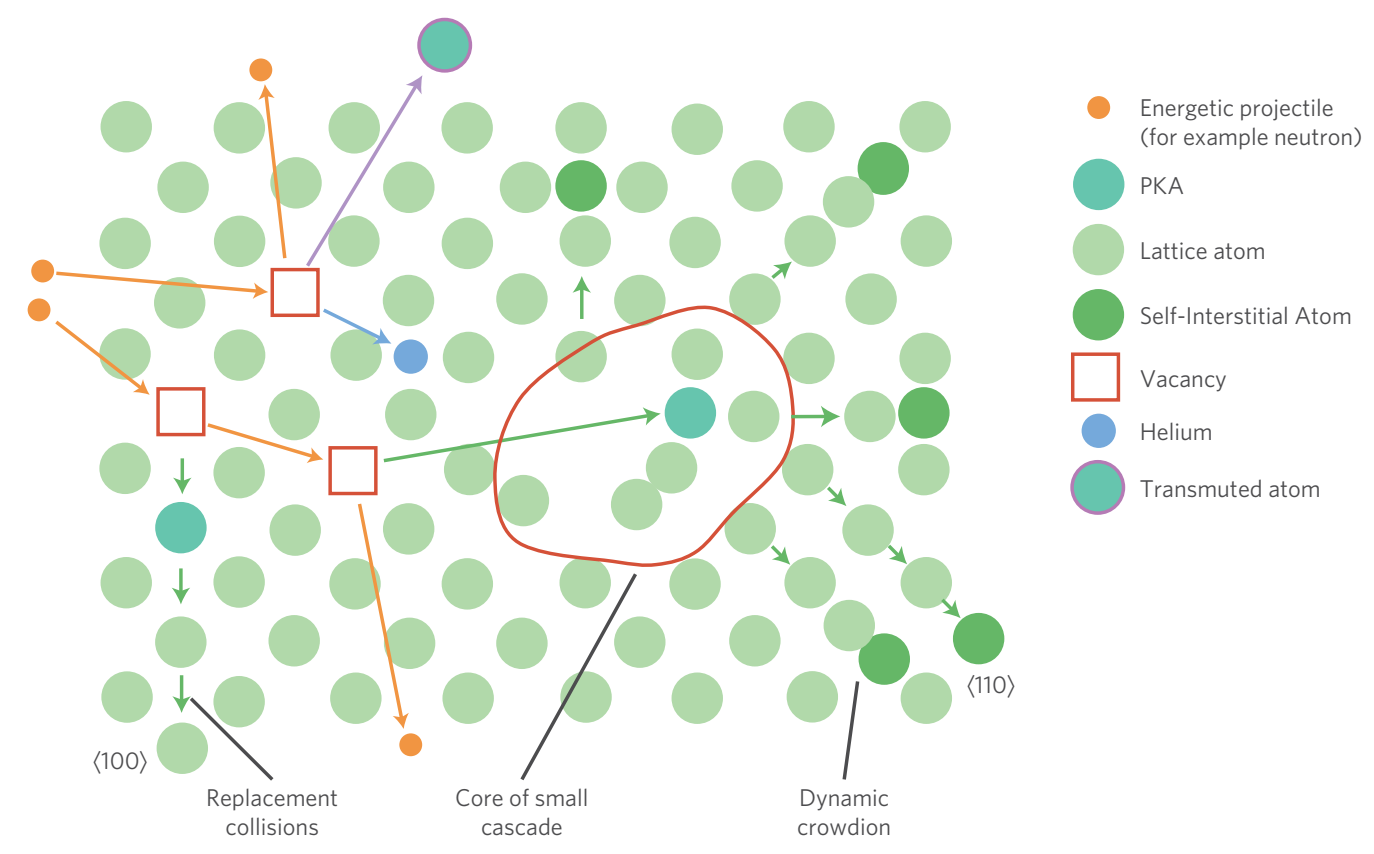

Figure 1 | Schematic illustration of irradiation damage. In the case of elastic scattering, projectiles with energy $E(<14.1$ MeV for fusion neutrons) are scattered at atoms of the impacted solid, thereby creating primary knock-on atoms (PKAs) in different directions and with different energies $E_{P K A}$. The PKA atom loses its energy $E_{\mathrm{PKA}}$ by damage production $\left(E_{\text {damage }}\right)$ as well as by ionization $\left(E_{\text {ionization }}\right)$, that is, $E_{\mathrm{PKA}}=E_{\text {damage }}+E_{\text {ionization }}$. The damage production energy, $E_{\text {damage, }}$ ranges from a threshold energy $E_{\text {threshold }}$ to $E_{\text {damage,max }}$, where $E_{\text {threshold }}$ is the orientation-averaged minimum energy for atom displacement from its regular lattice site. Typical values of $E_{\text {threshold }}$ are $40 \mathrm{eV}$ for Fe and $95 \mathrm{eV}$ for $\mathrm{W}$. The displaced atom, called the self-interstitial atom (SIA), can 'annihilate' with another vacancy ( $V$ ) or can share a regular lattice site with another atom (resulting in a 'crowdion'). In Fe and bcc steels, crowdions are stable in $\langle 110\rangle$ directions but mobile in $\langle 111\rangle$ directions. Replacement collisions along specific lattice directions are common for $E_{\text {damage }} \approx E_{\mathrm{d}}$ and displacement cascades (see also Fig. 2) happen for $E_{\text {damage }} \gg E_{d}$. Significant amounts of protons and $\alpha$-particles are created (for example, in steels) for threshold energies $E_{\text {threshold }, \mathrm{H}} \geq 2 \mathrm{MeV}$ and $E_{\text {threshold, } \mathrm{He}} \geq 5 \mathrm{MeV}$, respectively, by non-elastic transmutation reactions, leading to accelerated irradiation embrittlement.

properties. This is why research on materials with a high radiation resistance or a high radiation tolerance is still one of the highest priorities within the international fusion and fission communities.

The recoiling primary atom will mainly slow down owing to electronic inelastic interactions or elastic collisions with nearby atoms. The ratio of electronic versus nuclear stopping power and the rate at which energetic recoils lose kinetic energy are well understood in terms of Lindhard's theory ${ }^{17}$. Based on Lindhard's, Bethe's, Fermi's and Bohr's ${ }^{18-20}$ pioneering work, Ziegler, Littmark and Biersack ${ }^{21}$ developed a semi-empirical theory with universal screening functions able to predict with high accuracy the stopping and range distribution of energetic ions in almost any material. Meanwhile, the related Stopping and Range of Ions in Matter (SRIM) code has become a worldwide standard for the calculation of the stopping power and range of ions while flying through matter ${ }^{22}$.

The discovery of void swelling in neutron-irradiated stainless steels in 1966 by Cawthorne and Fulton ${ }^{23}$ made it clear that radiation effects might seriously impact the lifetime of fission reactors. In the early 1970s, one decade after the first Westinghouse commercial fission reactors were available, unprecedented damage levels started to appear in core components. This prompted the need for a measure of dose that could combine in a similar fashion all available existing irradiation data, irrespective of its nature and the substrate material. Kinchin and Pease $e^{24}$ had already proposed in 1955 that the displacements caused by fast neutron bombardment in fission reactors were produced in secondary collisions between moving interstitial atoms and stationary atoms. Thus, such collisions knocking out atoms would produce a distortion in the lattice by leaving behind a vacancy by the recoiling atom, which, in turn, would become an interstitial being lodged in a nearby location. They suggested that only atoms gaining more than some threshold energy $E_{\text {threshold }}$ are permanently displaced from the lattice, generating a point defect (a vacancy-interstitial pair also called a Frenkel pair ${ }^{25}$ ). In response to the worrisome damages observed in the early 1970s in fission reactors, the model of Kinchin and Pease was further developed jointly by a British, American and French international team led by Norgett, Robinson and Torrens for estimating the average number of atom displacements caused by a recoiling atom from a collision with an energetic particle, which culminated in 1975 with their modified Kinchin-Pease model $^{26}$. The total kinetic energy $E_{\mathrm{PKA}}$ of the PKA can be written as $E_{\mathrm{PKA}}=E_{\text {ionization }}+E_{\text {damage }}$, where $E_{\text {ionization }}$ stands for ionizationinduced heat production and $E_{\text {damage }}$, the so-called damage energy, for the displacement-induced damage (for example, cascades, vacancies and self-interstitial atoms). In their model, the estimate $v_{\mathrm{NRT}}$ of the number of Frenkel pairs in a given volume is proportional to $E_{\text {damage }}: v_{\mathrm{NRT}}=0.8 E_{\text {damage }} / 2 E_{\text {threshold }}$. Dividing $v_{\mathrm{NRT}}$ by the number of atoms in the given volume results in the Norgett-Robinson-Torrens displacement per atom $\left(\mathrm{dpa}_{\mathrm{NRT}}\right)$, a dimensionless quantity nowadays taken as an international standard ${ }^{27}$ for quantifying the average number of atomic displacements produced under cascade-damage conditions. The factor 0.8 in the above equation was determined from computer simulations based on binary collision models to account for realistic (that is, non-hard-sphere) scattering.

The $\mathrm{dpa}_{\mathrm{NRT}}$ measure incorporates, in a first approximation, the dependence of the response of the material under irradiation on the neutron energy; it has become the parameter for quantifying the damage in materials induced by radiation under a given neutron spectrum and flux. However, a frequent misuse of $\mathrm{dpa}_{\mathrm{NRT}}$ data is in equating $\mathrm{dpa}_{\mathrm{NRT}}$ to the damage in the material; but this disregards that $\mathrm{dpa}_{\mathrm{NRT}}$ does not account for relevant processes such as recombination, migration and coalescence of radiation defects. 
The $\mathrm{dpa}_{\mathrm{NRT}}$ represents an incomplete atom-based approximation of the neutron-irradiation-induced damage to materials. Although certainly a useful characteristic, it is to be used with caution when making decisions concerning a material's suitability for use in fusion set-ups ${ }^{28}$.

\section{Comparison of fusion and fission materials research}

Similar to fission neutrons, fusion neutrons gradually slow down in the materials and components surrounding the plasma, thereby efficiently losing their energy by creating displacement defects and heat. This heat is continuously extracted to produce electricity. However, unlike the fission neutrons (with a kinetic energy typically below $2 \mathrm{MeV}$ ), the $14.1 \mathrm{MeV}$ fusion neutrons can create not only $150-200 \mathrm{dpa}_{\mathrm{NRT}}$ in a replaceable blanket during five years of operation, but also substantial gaseous ( $\mathrm{H}$ and $\mathrm{He}$ ) and-depending on the alloy composition-solid transmutation products ${ }^{10}$, as described in more detail below. And unlike commercial water-cooled fission reactors, with their typical operating temperature near $570 \mathrm{~K}$, in-vessel fusion materials have to withstand $\sim 570-1,270 \mathrm{~K}$, according to today's divertor and blanket design principles. Depending on temperature and material's microstructure, $\mathrm{H}$ and $\mathrm{He}$ can substantially speed up the embrittlement of employed materials. A major critical issue of the international fusion materials research and development community is that the superposition of created transmutation products and displacement damage cannot be simulated by fission neutrons ${ }^{29-31}$.

Nevertheless, there have always been synergies between fusion and fission structural materials research. Attempts at correlating fission- and fusion-neutron-induced degradation have been made ${ }^{32-34}$. Unfortunately, for decades, tests were carried out with poor control of the irradiation characteristics, notoriously neglecting temperature variations of the irradiated material during reactor start-up and shutdown, which led to confusing data that were difficult to interpret. It was only in 1988 that Kiritani demonstrated how slight temperature changes in irradiated materials could strongly impact the resulting microstructural evolution ${ }^{35}$. The synergies and joint developments are nowadays stronger than ever, given the commonalities in the design concepts of fusion and Generation IV fission nuclear reactors regarding coolants and target operating temperatures ${ }^{36}$. Fusion materials research is a broad field connecting many different scientific communities worldwide; it addresses not only structural, but also functional materials ${ }^{37}$. It pervades a whole range of different lines of research, such as liquid-metal coolants for advanced in-vessel components ${ }^{38}$, structural materials with advanced radiation tolerance for the blanket ${ }^{39}$, fracture-toughness-improved refractory metals capable of holding $>10 \mathrm{MW} \mathrm{m}^{-2}$ peak power loads in the divertor ${ }^{40}$, neutron multipliers and ceramic breeders for efficient tritium fuel production (tritium self-sufficiency) ${ }^{41}$, multifilamentary superconducting wires forming cables capable of withstanding magnetic fields larger than $10 \mathrm{~T}$ and conducting currents of tens of $\mathrm{kA}^{42}$, suitable radiationresistant thermosets for the electrical insulation of the superconducting magnets ${ }^{43}$ and high-thermal-conductivity chemical vapour deposition (CVD) diamonds for plasma-heating systems ${ }^{44}$. It ranges from cryogenic temperatures in the superconducting magnets to above $1,000^{\circ} \mathrm{C}$ for the plasma-facing components in more exposed regions. It involves corrosion studies for assessing material compatibility under unique conditions, fabrication-processes development for timely (and affordably) meeting novel-material quantity needs, nuclear testing for understanding thermo-electromechanical degradation phenomena and much more.

\section{Modern tools for nuclear materials research}

A comprehensive understanding of the mechanisms of irradiation damage in condensed matter in time and space is essential for

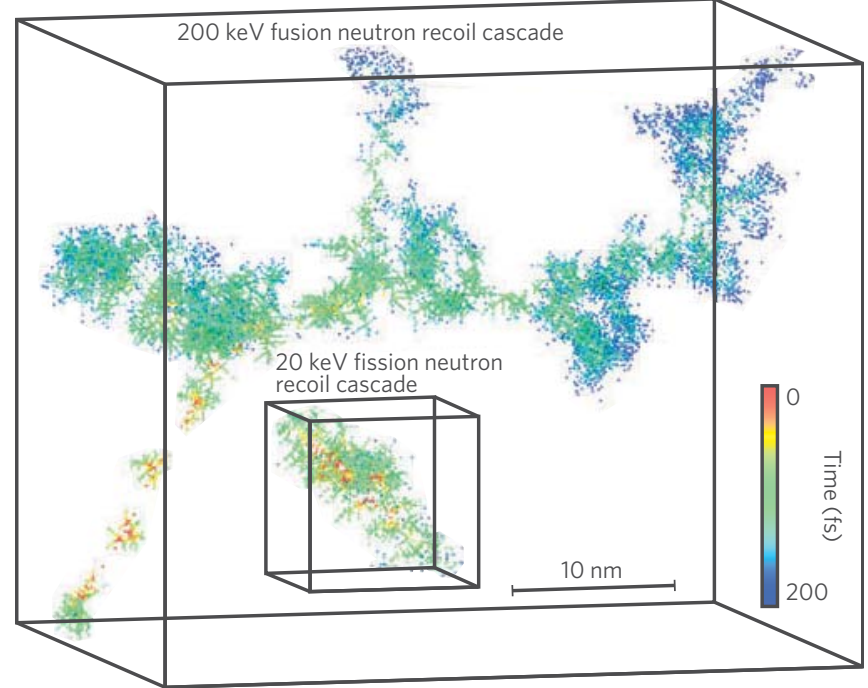

Figure 2 | Evolution of a typical morphology cascade in pure iron triggered by a $20 \mathrm{keV}$ fission and a $200 \mathrm{keV}$ fusion neutron calculated by means of molecular dynamics (Courtesy of Andrea Sand and Kai Nordlund.). The colours of the atoms correspond to the times when their kinetic energy becomes $>5 \mathrm{eV}$. The more severe damage caused by the $200 \mathrm{keV}$ neutron is seen to reach the $200 \mathrm{fs}$ timescale, compared with the $100 \mathrm{fs}$ range reached by the $20 \mathrm{keV}$ neutron. The dimensions of the cubes are in the $10 \mathrm{~nm}$ range.

the development and optimization of advanced fusion materials. The physics of primary damage production in low- and highenergy displacement cascades has been studied in detail with molecular dynamics (MD) simulations, despite the sometimes limited accuracy of the underlying potentials. Once a PKA is formed by an impacting high-energy neutron, it immediately transfers its energy to its surrounding atoms, creating displacement cascades. In Fig. 2, the evolution of a typical displacement cascade in pure iron triggered by an energetic fusion neutron is shown, compared with the damage caused by a fission neutron, calculated in a molecular dynamics simulation. The damage and its evolution in time (nanoseconds to years) and space determines the macroscopic response of a material to irradiation, and is thus crucial for understanding and predicting the evolution of the physical properties of structural and functional materials exposed to high fluences of fusion neutrons. A large number of atoms is initially displaced (quantified by $\mathrm{dpa}_{\mathrm{NRT}}$ ), but when the cascade cools down within less than a nanosecond, most of them return to perfect crystalline positions - the athermal recombination effect. However, many atoms do not return to their original position, and hence the number of atom replacements is significantly larger than the number of defects produced. Frenkel defects often undergo longrange migration to interfaces, thereby enhancing alloy dissolution, segregation and grain-boundary embrittlement. In other words, the high Frenkel defect concentration often results in substantially accelerated materials ageing. On the other hand, most of the surviving defects either form vacancy-type voids or stable interstitial $2 \mathrm{D}$ and $3 \mathrm{D}$ clusters, acting as barriers to the motion of dislocations, and leading to substantial irradiation hardening, fracture toughness and ductility reduction. For a given material and temperature, each neutron energy creates its own statistical balance between Frenkel defects and high-energy cascades, ending up in a specific irradiation-modified microstructure.

The effects of irradiation on a material's microstructure and properties are a classic example of an inherently multiscale phenomenon, as schematically illustrated in Fig. 3a. Length scales 
of relevant processes range from $\sim 1 \AA$ to structural-component lengths, spanning more than 12 orders of magnitude. In turn, the relevant timescales cover more than 22 orders of magnitude, with the shortest being in the femtosecond range $e^{45}$. So, to understand the irradiation-induced or -assisted degradation of large-scale components such as the blanket of a typical demonstration fusion reactor (the yellow component in Fig. 3a) and to accelerate related materials research and development, studying structureproperty relations is indispensable. A scientific approach based on integrated experimental and computational modelling for investigating the degradation of materials under irradiation is shown in Fig. 3b. Today, a multiscale approach, based on both computational materials science and high-resolution experimental validation, is used to understand the controlling mechanisms and processes of irradiated structural materials ${ }^{46}$. Figure $3 \mathrm{~b}$ illustrates the hierarchical multiscale modelling methodology, which typically combines $a b$ initio structure calculations on the atomic scale $^{47-50}$, molecular dynamics simulations $s^{51-53}$, kinetic Monte Carlo $^{54,55}$ simulations, discrete dislocation dynamics ${ }^{56,57}$, and rate theory ${ }^{58}$ with continuum calculations including thermodynamics and kinetics ${ }^{59,60}$, as well as phase field calculations ${ }^{61}$. Ab initio methods are required to calculate the most stable defect-cluster configurations, their dissociation energies, or the most likely lattice diffusion paths. Results of $a b$ initio studies can be used as input for molecular dynamics, kinetic Monte Carlo, rate field theory and thermodynamics calculations. Additional links between different simulation methods are indicated by the arrows in Fig. 3b. It is important to note that, for the verification of computational modelling results, sophisticated experimental validation technologies are used, including in situ micromechanics, high-resolution electron microscopy techniques, atom-probe tomography, as well as neutron and X-ray scattering sources. This integrated computational and experimental modelling approach is particularly challenging because it has to combine more conventional structure-property correlations and fusion-specific irradiation-induced defect features.

\section{In-vessel components}

The most urgent materials developments required for fusion reactors beyond ITER, at present the worlds' largest scientifictechnical enterprise ${ }^{62}$, are related to the in-vessel components of tokamaks, with the blanket and the divertor being the most relevant. Inherently, stellarators have equal materials issues, despite their operational regime being different from that of tokamaks. (Tokamaks operate in a pulsed/quasi-steady mode with potential plasma disruptions, whereas stellarators operate completely steadily without disruptions.) Therefore, most fusion materials research is carried out with both technologies in mind-although some aspects do need separate investigations, for example, the issue of replacing components of a stellarator. In a tokamak, the blanket covers the interior surfaces of the vacuum vessel, providing suitable shielding from heat and neutrons to the vessel and the superconducting magnets. In turn, the divertor is the exhaust system of the confined plasma that extracts helium ash and other impurities, mainly resulting from erosion of the plasma-exposed surface (absorbing $\sim 20 \%$ of fusion energy). In addition, the breeding of tritium during operation to fuel the plasma is indispensable for the reactor self-sufficiency; this will be achieved through ${ }^{6} \mathrm{Li}(n, t)^{4} \mathrm{He}$ or ${ }^{7} \mathrm{Li}(n, n t)^{4} \mathrm{He}$ reactions in the blanket (enhanced by neutronmultiplier functional materials such as $\mathrm{Be}$ or $\mathrm{Pb}$ ) - one of ITER's goal is to demonstrate this with the test blanket module ${ }^{63}$.

In fusion reactors, the induced currents and magnetic fields, together with thermomechanical loads, may lead to unprecedented multidirectional cyclic stresses caused by Lorentz forces, which in the case of the in-vessel components demands superior mechanical performance during the maximum possible operational time period a

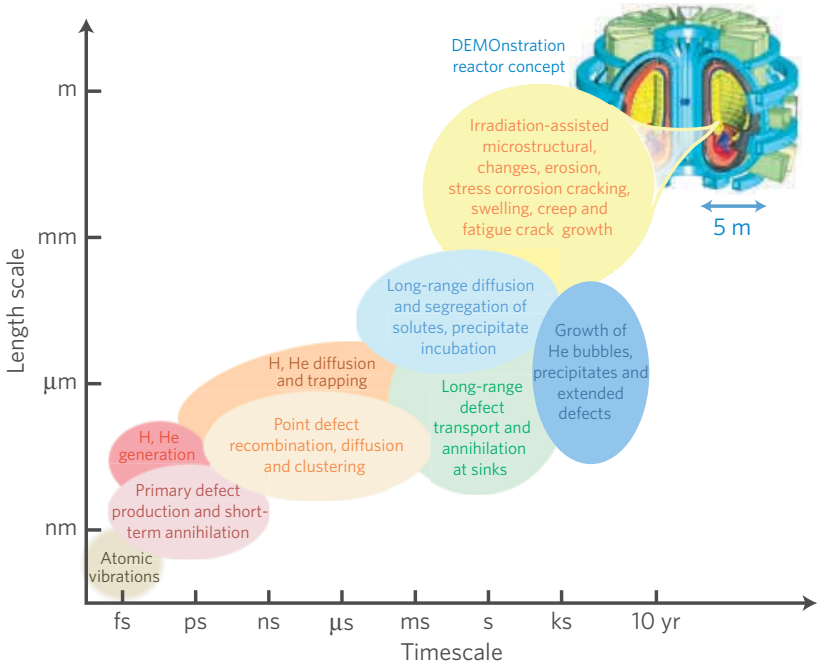

b

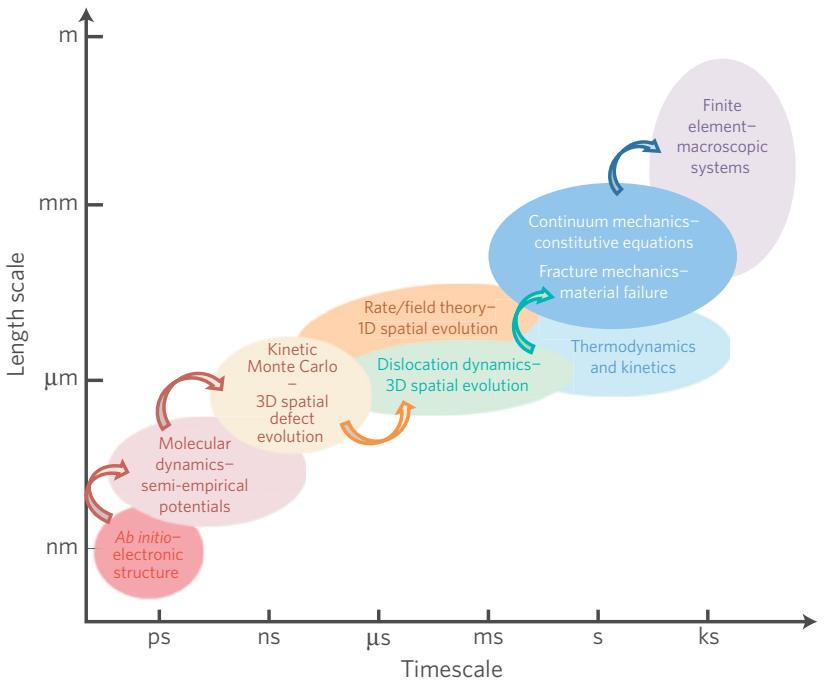

Figure 3 | a, Schematic illustration of time and length scales of multiscale damage processes responsible for microstructural changes and resulting property degradation during high-energy neutron irradiation of plasma-near in-vessel materials. The evolving microstructural changes (yellow and blue ellipses) substantially affect, in turn, defect nucleation and growth at the nanoscale. b, Typical integrated computational materials science (CMS) methods used for understanding irradiation-induced structure-property correlations and assisting material research and development. Today, there is strong interaction between CMS method development and dedicated validation experiments.

to minimize the need of costly and difficult preventive maintenance shutdowns. In fusion power plants, heat is generated from the kinetic energy of neutrons, which are slowed down in the blanket and absorbed by coolants, so the materials must be capable of withstanding intense irradiation for long periods.

One of the major international achievements during the past three decades was the successful development of so-called lowor reduced-activation materials. Their composition should make activation as low and quickly decaying as possible, thus allowing simple re-use or disposal. As a result, the main alloying elements of candidate fusion structural materials should consist of the following elements to meet low-level waste criteria: $\mathrm{Fe}, \mathrm{Cr}, \mathrm{Ti}, \mathrm{V}$, W, Si and C (refs 64,65). Ferritic-martensitic steels with chromium concentrations ranging from 8 to $12 \%$ have been the subject of intense study for three decades already owing to their irradiation 
resistance, low activation through suitable alloying and their significantly lower swelling than stainless steels. They are considered the reference structural material, at least for the first generation of future fusion reactors, given their technological maturity, developed fabrication routes, mastered joining technology and worldwide industrial experience. Today, reduced-activation steels are highpurity steels of the type (8-9)Cr-(1-2)WVTa by replacement of $\mathrm{Mo}, \mathrm{Nb}$ and $\mathrm{Ni}$ by $\mathrm{W}$ and $\mathrm{Ta}$ as alloying elements. Compared to conventional steels, which need about 200,000 years to achieve 'lowlevel waste' criteria after five years irradiation in a fusion power reactor, the reduced-activation alloys reach this criterion already within $80-100$ years. Yet, alternative materials might still improve performances. Silicon carbide composites are candidates, but at present exhibit low thermal conductivity and insufficient fracture toughness ${ }^{66}$. Vanadium alloys are another possibility, but they still suffer from low-temperature irradiation embrittlement ${ }^{67}$.

The choice of the structural material for the blanket affects the design and efficiency of a power plant; a wide combination of materials and coolants is being considered for future tokamaks and upgrades. The operational-temperature range for ferritic martensitic steels, which cannot at present be used well above $550^{\circ} \mathrm{C}$, would possibly allow a water-cooled ceramic tritium breeder system. In turn, whereas silicon carbide composites could allow the construction of $1,000{ }^{\circ} \mathrm{C}$ helium-cooled tritium breeding blankets, vanadium alloys would probably be cooled with liquid lithium or a lithium-lead eutectic above $650{ }^{\circ} \mathrm{C}$ (ref. 68). Enhancement of the operational temperature to above $700{ }^{\circ} \mathrm{C}$ could also be realized with nanostructured oxide-dispersion-strengthened (ODS) steels, where embrittlement is mitigated by dispersed $\mathrm{Y}_{2} \mathrm{O}_{3}$ particles that become effective sinks for trapping point defects and helium atoms, preventing their migration ${ }^{69}$ and coalescence leading to swelling; unfortunately, this approach has not been industrialized yet.

Blanket structural materials must have an optimal overall balance between mechanical properties such as strength, ductility, fracture toughness, thermal and irradiation creep, fatigue, crack growth under cyclic stresses and optimal corrosion resistance to whichever coolant is used. Irradiation generates obstacles to the motion of dislocations through atomic displacement and transmutation products. Given that the size and the density of defects are functions of temperature, radiation strengthening depends on the temperature of the irradiated material. In fusion reactors, the 14.1 MeV neutrons will lead to a helium production ratio of around $12 \mathrm{appm} / \mathrm{dpa}_{\mathrm{NRT}}$, mainly through ${ }^{56} \mathrm{Fe}(n, \alpha){ }^{53} \mathrm{Cr}$ reactions (in fast-fission reactors, this ratio is $0.3 \mathrm{appm} / \mathrm{dpa}$, owing to the $3.7 \mathrm{MeV}$ threshold of the reaction ${ }^{70}$ ). The accumulation of helium leads to a significant mechanical impact even with low concentrations; helium-induced embrittlement, observed in fission reactors, is a major concern for fusion materials. Conversely, the high permeation of hydrogen, mainly generated through ${ }^{56} \mathrm{Fe}(n, p){ }^{56} \mathrm{Mn}$ reactions at a rate of $45 \mathrm{appm} / \mathrm{dpa}$, makes the potential degrading impact of hydrogen less relevant, although a combined detrimental enhancement of both helium and hydrogen is expected. The metal's microstructure is substantially changed by the nucleation and growth of the increasingly dense population of helium atoms forming bubble clusters that will degrade the metal's mechanical properties ${ }^{71}$. In particular, whereas for nonirradiated ferritic martensitic steels the ductile-to-brittle transition temperatures lie close to $-100^{\circ} \mathrm{C}$, a rapid shift towards values above room temperature, which would demand their replacement after a much shorter time, occurs above $30 \mathrm{dpa}_{\mathrm{NRT}}$ (ref. 36). An efficient annealing of irradiation damage with substantial recovery of irradiation embrittlement and related brittle-to-ductile transition temperature has been demonstrated by Fletcher in $1953^{72}$, and experimentally confirmed for ferritic martensitic steels $\mathrm{s}^{73,74}$ on fission reactor irradiation; however, whether fusion-specific high helium

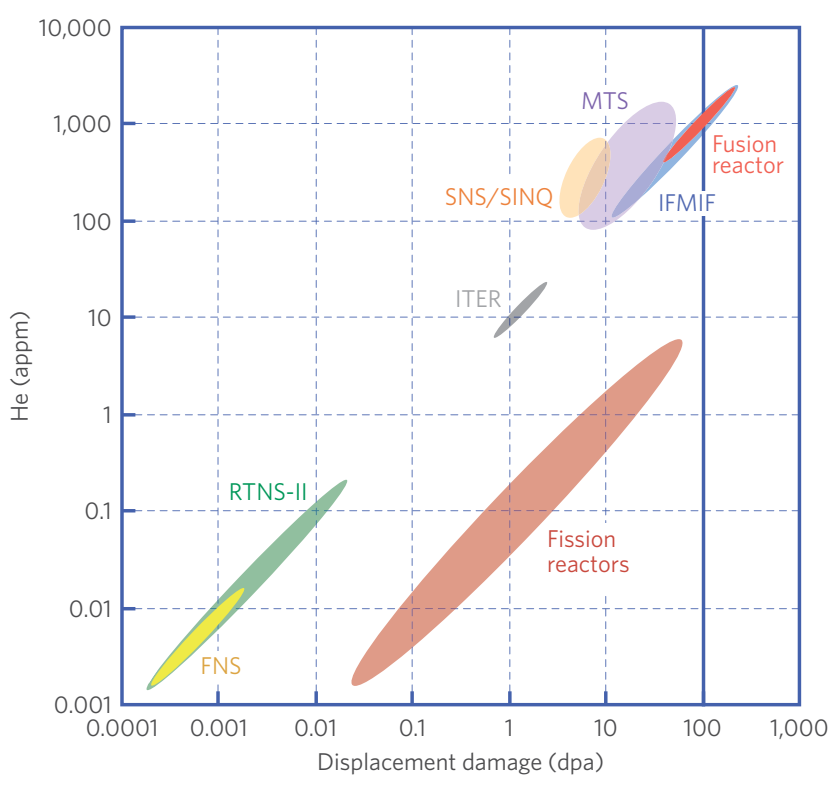

Figure 4 | Graph showing the correlation of dpa $a_{\text {NRT }}$ versus appm of $\mathrm{He}$ generated for the different possibilities of testing materials (alternative and IFMIF) compared with fusion reactor conditions (modified from Figure 3 of ref. 31). MTS, Materials Test Station spallation source at Los Alamos National Laboratory; RTNS-II, Rotating Target Neutron Source-II, previously at Lawrence Livermore National Laboratory; SINQ, the SwisS Spallation Source at Paul Scherrer Laboratory; SNS, Spallation Neutron Source at Oak Ridge National Laboratory; FNS, Fusion Neutron Source at Japan Atomic Energy Agency.

concentrations prevent recovery can be answered only by means of a dedicated fusion neutron source.

\section{Testing structural materials for fusion}

A wide variety of irradiation facilities have been proposed to both investigate materials science phenomena and to collect more-orless appropriate data for pre-conceptual designs of demonstration fusion reactors. Unfortunately, it is at present not possible to reliably predict the degradation of materials exposed to fusion reactions for a long time with the available data: extrapolations lead to inconclusive results (see Fig. 4).

Testing facilities with a $14.1 \mathrm{MeV}$ neutron source for irradiating candidate materials under fusion-reactor conditions and offering control of the temperature of the irradiated material have become an urgent need, and now feature in fusion roadmaps ${ }^{75}$. Such facilities would help materials scientists to understand the physics at play, in the same way that successful theoretical models and computer simulations have significantly contributed to unravelling the complex physics of fission neutrons observed in experiments. Traditionally, the lack of a fusion-relevant source for materials testing has been bypassed mainly via two approaches, both with serious shortcomings: first, using steels doped with boron, which given their low solubility tend to segregate, leading to a nonuniform helium distribution, or doped with nickel, which impacts on the martensitic phase of the steels, leading to austenite formation; and second, by bombardment with $\alpha$-particles with energies in the range $20-100 \mathrm{MeV}$ produced by cyclotron facilities, which can result in $\mathrm{He} / \mathrm{dpa}_{\mathrm{NRT}}$ ratios of $10,000 \mathrm{appm} / \mathrm{dpa}$ with ranges typically of the order of micrometres, resulting in very thin layers difficult to characterize ${ }^{29}$. Obstacles to efficiently extrapolating data from fission reactors have already been addressed. In turn, spallation sources produce a neutron spectrum with high-energy tails, reaching the energy of the colliding protons (that is,
67 
beyond $580 \mathrm{MeV})^{76,77}$. As a consequence, spallation sources produce $\mathrm{He} / \mathrm{dpa}_{\mathrm{NRT}}$ and $\mathrm{H} / \mathrm{dpa}_{\mathrm{NRT}}$ ratios that are 5-10 times above fusionspecific ratios, they also lead to a variety of solid transmutations such as $\mathrm{Ca}, \mathrm{S}, \mathrm{P}$, the related impact uncertainties of which are a main concern for their utilization in fusion materials studies. In addition, the effect of spallation neutrons being pulsed on a material's degradation is not well understood, which leads to further uncertainties.

The international efforts to develop a neutron source for fusion materials research through $\operatorname{Li}(d, x n)$ nuclear reactions started in the 1970s (ref. 78), and materialized in the 1980s with the Fusion Materials Irradiation Test (FMIT) facility ${ }^{79}$. However, neither was the technology mature nor was the urgency for $14.1 \mathrm{MeV}$ neutrons acute-now both aspects have evolved and the need for a test facility is relevant more than ever. ITER will suffer a maximum irradiation damage below $3 \mathrm{dpa}_{\mathrm{NRT}}$ at the end of its designed operational life; available data and current understanding of the behaviour of irradiated structural materials are sufficient to anticipate the damage. However, for a $3 \mathrm{GW}$ thermal power fusion reactor, neutron fluxes in the blanket above $10^{19} \mathrm{~m}^{2} \mathrm{~s}^{-1}$ will have to be tackled, corresponding to a damage level above $20 \mathrm{dpa}_{\text {NRT }}$ per full power year.

An alternative idea for a fusion-relevant neutron source facility was developed based on the more conventional carbon-rotatable target, which would require 1.2 $\mathrm{MW}$ average beam power to achieve $>20 \mathrm{dpa}_{\mathrm{NRT}}$ in $25 \mathrm{~cm}^{3}$ per year. Unfortunately, such beam power, being essentially one order of magnitude higher than what has been reliably achieved up to now, would require an aggressive target development programme ${ }^{80}$, with risks of facing unsolvable technical difficulties. At the same time, the idea of a $\operatorname{Li}(d, x n)$ neutron source was never abandoned, and has matured throughout the past decades. The International Fusion Materials Irradiation Facility (IFMIF, see Fig. 5 and Box 1) is successfully developing its Engineering Validation and Engineering Design Activities (EVEDA) phase under the Broader Approach Agreement between Japan and EURATOM in the field of fusion energy research ${ }^{81}$, with the goal of being ready for the construction of a $\operatorname{Li}(d, x n)$ facility capable of providing $>20 \mathrm{dpa}_{\mathrm{NRT}}$ year in a volume of $500 \mathrm{~cm}^{3}$ (see Box 1). The cost of such a facility would be marginal compared to the future cost of a fusion reactor, and could be ready, thanks to IFMIF/EVEDA, within less than one decade from the moment of the decision to construct it. Higher testing volumes will be needed in the future to allow testing the performance of required equipment under irradiation; this can be achieved only with a fusion reactor ${ }^{82,83}$, similarly to the way fission materials have always been tested in experimental fission reactors. However, such an experimental fusion reactor would face structural materials problems and would certainly profit from the results of a $\operatorname{Li}(d, x n)$ facility to be reliably designed ${ }^{84}$. Unfortunately, whereas a fission reactor can be sized down, a fusion reactor retains certain size and complexity limitations, which tend to correlate with cost.

\section{Progress in plasma-facing materials research}

Materials capable of withstanding extreme heat loads in addition to neutron bombardments are required for the plasma-facing components. The irradiation damage becomes secondary compared to the high generated thermal power densities (up to $20 \mathrm{MW} \mathrm{m}^{-2}$; refs 85,86 ) in the divertor armour, the lifetime of which could be limited to two years owing to erosion phenomena (which could still be affordable given the relative ease of removal compared with that of the blanket). The key properties of plasma-facing components are thermal conductivity, strength, ductility, thermal shock resistance, thermal fatigue resistance, structural stability at high temperature, low activation and stability of all these properties under long-term irradiation with $14.1 \mathrm{MeV}$ neutrons ${ }^{87}$. Finding a material with optimal behaviour regarding all these properties is an impossible challenge. Despite the partly contradictory properties, such as strength and ductility, tungsten is at present considered the most promising material over carbon/carbon fibre composites ${ }^{88}$, beryllium ${ }^{89}$ or other refractory metals. Tungsten has the highest melting point $\left(3,410^{\circ} \mathrm{C}\right)$ and lowest vapour pressure $\left(1.3 \times 10^{-7} \mathrm{~Pa}\right.$ at its melting temperature), which makes it a good material for sustaining high temperatures in ultrahigh vacuum conditions. In addition, it has high thermal conductivity, high energy threshold for sputtering (preventing erosion), low swelling and low tritium retention. However, tungsten has a high atomic number, which is detrimental for plasma ignition because it would cool the plasma if it is present as an impurity beyond certain limits, poor machinability, and it cannot strictly be called a structural material because of its brittleness, as is the case with other refractory metals of group VI, with a ductile-to-brittle transition temperature above $700^{\circ} \mathrm{C}$, even in non-irradiated state, in the presence of residual stresses. Fortunately, ductility at low temperatures can be obtained if interstitial solute elements, segregating at grain boundaries and behaving as inclusions, are minimized and grain sizes are reduced. In addition, transmutation products such as rhenium (which could also be suitably alloyed) that become a substitutional solute in the tungsten lattice ${ }^{90}$ seem to substantially mitigate radiationinduced swelling. The open routes for improving the mechanical properties of tungsten are numerous and cannot be described in detail here (for an overview, see refs 87,91), but the road ahead looks promising. There is little existing data on the degradation of fracture toughness under $14.1 \mathrm{MeV}$ neutrons; however, the high melting temperature of tungsten allows operational temperatures above $900^{\circ} \mathrm{C}$ that would lead to a self-annealing minimizing the irradiation hardening effect. Nevertheless, this could be the case only in the most exposed regions, because the heat sink is constructed with materials such as $\mathrm{Cu}$ that cannot operate at these temperatures; furthermore, bonding to substrate materials could be damaged, leading to unaffordable increases in thermal contacts. At the same time, a higher operational-temperature limit exists to avoid re-crystallization, which occurs above $1,200^{\circ} \mathrm{C}$ with a loss of toughness ${ }^{92}$; a lot of research is being done to find suitable alloying capable of increasing this temperature. Tungsten-based materials are suitable for the divertor armour of fusion reactors and also for the first wall of fusion power plants; research is continuing to find an optimal joining or application of thin layers capable of withstanding the thermal stresses between a tungsten coating and the substrate material to ensure an optimal thermal contact during operation ${ }^{90}$. Regarding safety aspects, tungsten and the alloying of heavy isotopes present high inelastic cross-sections with respect to $14.1 \mathrm{MeV}$ neutrons, but with relatively short lifetimes. However, possibly the main concern is related to tritium retention, which is at present not completely understood ${ }^{93}$ and could have an impact on the tritium fuelling. Testing suitable plasma-facing materials at fusion-reactor-relevant operational conditions is being intensively researched. Tests are carried out on actively cooled mock-ups with pre-defined power densities. Static heat loads in a fusion reactor are typically simulated either with stepwise increased power densities to determine the heat-removal capability of a given geometry or cycled to explore thermal fatigue behaviour. Given the differences in the testing parameters among the existing facilities, attempts to find a correlation between the available results showed differences in the evolution of the surface temperatures with power densities ${ }^{94}$ The most common testing approach with electron gun $\mathrm{s}^{95-102}$ has the advantage of allowing a homogeneous heat loading on large areas and flexible operation with suitable pulse lengths; other methods use $\mathrm{H}^{+}$beams ${ }^{103}$ or infrared heaters ${ }^{104}$. Thermal shock scenarios during plasma disruptions or vertical displacement events have also been tested with plasma guns, which have the advantage of having a small penetration depth, similar to the surface heat loads during operation, which also allows testing the combined effect with magnetic fields and with high-power laser facilities ${ }^{105}$. ITER divertor 


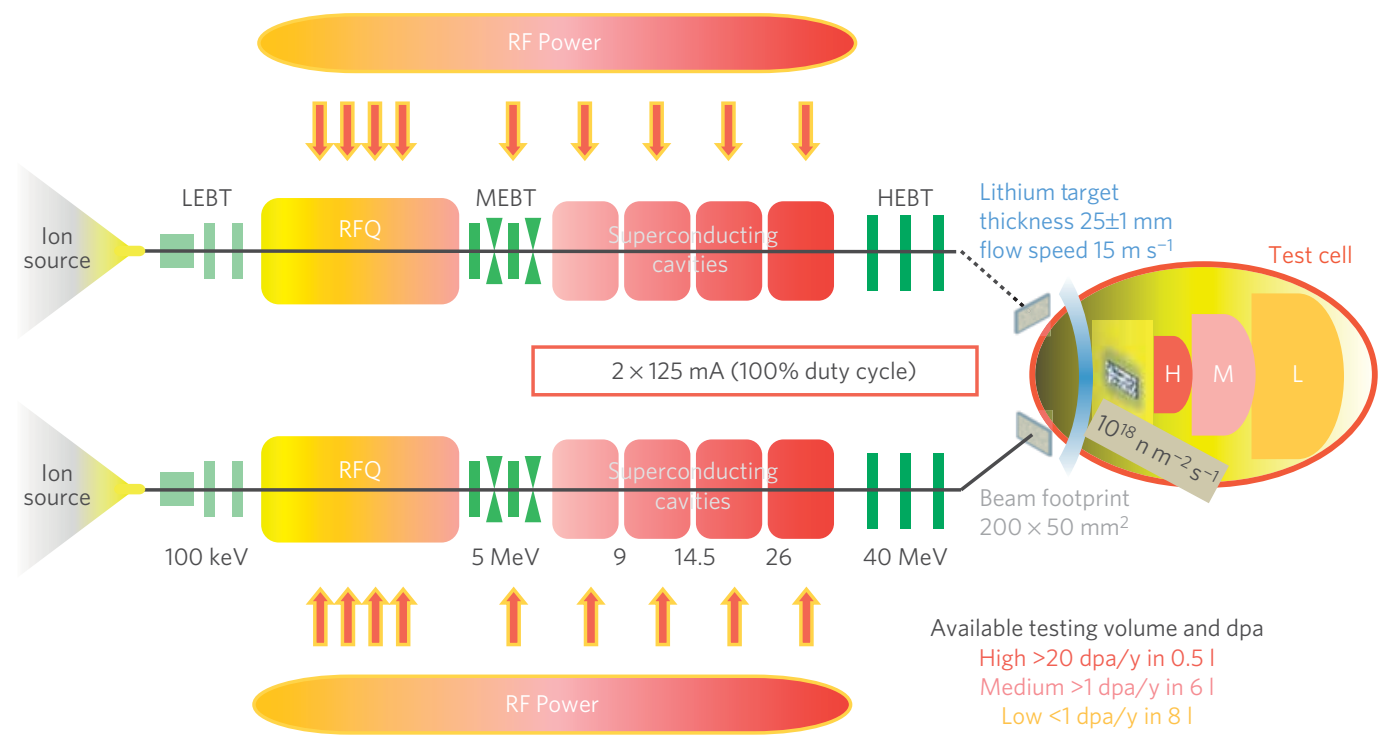

Figure 5 | Schematic of the International Fusion Materials Irradiation Facility with its two deuteron accelerators of $125 \mathrm{~mA}$ in CW mode at $40 \mathrm{MeV}$ impacting with a beam footprint of $200 \mathrm{~mm} \times 50 \mathrm{~mm}$ on a $15 \mathrm{~m} \mathrm{~s}^{-1}$ lithium flow at $250^{\circ} \mathrm{C}$. The lithium screen has a twofold function: first, to absorb the $2 \times 5 \mathrm{MW}$ beam power, and second, to react with the deuterons to generate the neutron flux. The range of deuterons in lithium is $\sim 20 \mathrm{~mm}$, therefore the flowing lithium screen of thickness $25 \pm 1 \mathrm{~mm}$ thick completely absorbs the impacting deuterons. A concave shape with a $250 \mathrm{~mm}$ radius routes the lithium, causing an increase of the pressure by centrifugal forces that prevents boiling conditions during operation ${ }^{114}$. The remote handling replacement of this backplate has been validated with a full-scale mock-up in Brasimone, Italy $\mathrm{y}^{115,116}$. A flux of neutrons of $10^{18} \mathrm{~m}^{-2} \mathrm{~s}^{-1}$ is generated in the forward direction, mainly through the $\mathrm{d}$-Li stripping reaction, $\mathrm{Li}(d, n) \mathrm{Be}$, with energy $\sim 0.4 E_{\text {deuteron, }}$, but also other nuclear $\mathrm{Li}(d, x n)$ reactions are available ${ }^{117}$. The fusion-relevant neutron flux is capable of providing $>20 \mathrm{dpa}_{\mathrm{NRT}}$ in $500 \mathrm{~cm}^{3},>1 \mathrm{dpa}$ NRT/year in $6,000 \mathrm{~cm}^{3}$ and $<1 \mathrm{dpaNRT} /$ year in $8,000 \mathrm{~cm}^{3}$ to the High, Medium and Low Test Modules ${ }^{118}$, respectively, in the Test Cell. The $500 \mathrm{~cm}^{3}$ available testing volume in the High-Flux Test Module will house more than 1,000 small specimens irradiated simultaneously in 12 capsules that are independently cooled at the selected irradiation temperatures within the $250-550^{\circ} \mathrm{C}$ range $\mathrm{e}^{118,119}$
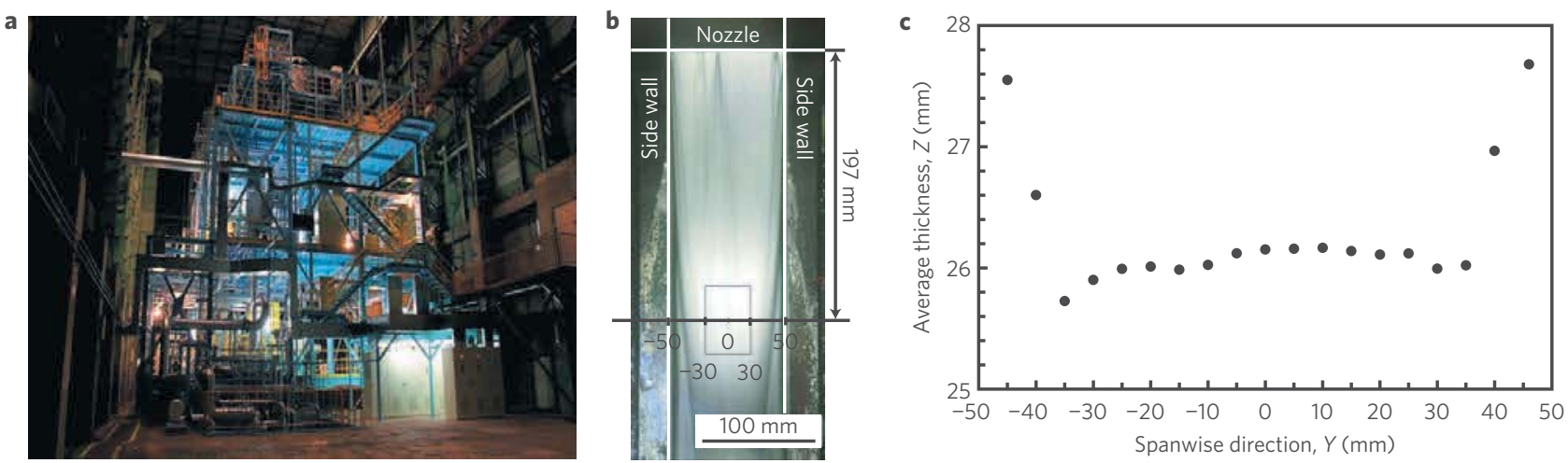

Figure 6 | a, Photo of the EVEDA Lithium Test Loop (ELTL) on 19 November 2010 on completion of its construction. It was damaged during the East Japan Earthquake of 11 March 2011, but remained in operation until October 2014, successfully demonstrating the long-term stability of IFMIF's lithium target operational conditions ${ }^{120,121}$. b. Flow appearance of lithium target pictured on the final day of the validation activities (31 October 2015) with flow conditions $15 \mathrm{~m} \mathrm{~s}^{-1}$, pressure $120 \mathrm{kPa}$, and temperature $250^{\circ} \mathrm{C}$. c. Average thickness of $\mathbf{b}$ at the beam centre axis $(Y)$ as per IFMIF backplate tested measured by a laser-probe method ${ }^{122}$ (note the increased thickness of $\sim 26 \mathrm{~mm}$ during operation anticipated by fluid dynamics). The operation time of the lithium target accumulated from the different phases of the commissioning was 1,560 h.

technology will be tested under ITER-relevant conditions in the WEST (W-tungsten Environment in Steady-state Tokamak) project, at present under construction in France, transforming the Tore Supra tokamak into one with an X-point divertor configuration with a new long-pulse capability, enabling extensive testing under power densities reaching $20 \mathrm{MW} \mathrm{m}^{-2}$ and ITER-like fluences (pulses of $1,000 \mathrm{~s})^{106}$.

\section{Perspectives}

Suitable materials for a safe, reliable, low-activation and longterm operational interface between an ignited plasma and the next generation of magnetic-confinement fusion reactors capable of withstanding severe irradiation, cyclic stresses, heat loads and plasma-induced erosion is becoming a reality thanks to international collective endeavours that have been going on for decades. Fusion materials research is a discipline in continuous maturation since the $1970 \mathrm{~s}^{30,31,107-113}$. The global fusion energy community is developing further the dream of bringing the Sun's power generator to Earth, in one of the most fascinating scientific adventures ever undertaken. We are getting nearer to commercial fusion power owing to the continuous positive slope in its maturing process, which is the result of the never-ceasing efforts of fusion 
scientists and governmental support towards this reachable dream of an inexhaustible and safe source of energy. Lev Artsimovich, one of the founders of the tokamak concept, was asked, at the dawn of fusion research, when commercial fusion power would become available. He said: 'Fusion will be ready when society needs it, maybe even a short time before that'.

\section{Received 1 October 2015; accepted 17 March 2016; published online XX Month XXXX}

\section{References}

1. Eddington, A. The internal constitution of the stars. Observatory 43 341-358 (1920).

2. Lawson, J. D. Some criteria for a power producing thermonuclear reactor. Proc. Phys. Soc. B 70, 6-10 (1957).

3. Wigner, E. P. Theoretical physics in the metallurgical laboratory of Chicago. J. Appl. Phys. 17, 857 (1946).

4. Robinson, M. T. Basics physics of radiation damage production. J. Nucl. Mater. 216, 1-28 (1994)

5. Zinkle, S. J. Comprehensive Nuclear Materials Vol. 1 Ch. 3 (Elsevier, 2012).

6. Nordlund, K. et al. Primary Radiation Damage in Materials NEA/NSC/DOC(2015)9.

7. Greenwood, L. R. Neutron interactions and atomic recoil spectra. J. Nucl. Mater. 216, 29-44 (1994).

8. Noda, T. et al. Transmutation and induced radioactivity of $\mathrm{W}$ in the armo and first wall of fusion reactors. J. Nucl. Mater. 258-263, 934-939 (1998).

9. Tanno, T. et al. Effects of transmutation elements on the microstructural evolution and electrical resistivity of neutron-irradiated tungsten. J. Nucl. Mater. 386-388, 218-221 (2009)

10. Fischer, U. et al. Transmutation behaviour of Eurofer under irradiation in the IFMIF test facility and fusion power reactors. J. Nucl. Mater. 329-333, 228-232 (2004)

11. Kiritani, M. Defect structure evolution from radiation damage with D-T fusion neutrons. J. Nucl. Mater. 133, 134, 85-91 (1985).

12. Mansur, L. et al. Mechanical properties changes induced in structural alloys by neutron irradiations with different helium to displacement ratios. J. Nucl. Mater. 155-157, 130-147 (1988)

13. Sigmund, P. Theory of sputtering. I. Sputtering yield of amorphous and polycrystalline targets. Phys, Rev. 184 (1969).

14. Stoeklin, G. Chemie Heisser Atome (Verlag Chemie, 1969).

15. Parkin, D. M. \& Coulter, C. A. Displacement cascades in polyatomic materials. J. Nucl. Mater. 117, 340-344 (1983).

16. Muroga, T. et al. The effect of recoil energy spectrum on cascades structure defect production efficiencies. J. Nucl. Mater. 133, 134, 378-382 (1985).

17. Lindhard, J. \& Winther, A. Stopping power of electron gas and equipartition rule. Mat. Fys. Med. Dan. Vid. Selsk. 34 (1964).

18. Bethe, H. A. Bremsformel für Elektronen relativistischer Geschwindigkeit. Z. Phys. 76, 293 (1932)

19. Fermi, E. The ionization loss of energy in gases and in condensed materials. Phys. Rev. 57, 485 (1940).

20. Bohr, N. Scattering and stopping of fission fragments. Phys. Rev. 58, 65 (1940).

21. Ziegler, J. F., Biersack, J. P. \& Littmark, U. The Stopping and Range of Ions in Matter Vol. 1 (ed. Ziegler, J. Z.) (Pergamon, 1985)

22. Ziegler, F. http://www.srim.org/

23. Cawthorne, C. \& Fulton, E. J. Voids in irradiated stainless steel. Nature 216 (1967).

24. Kinchin, G. H. \& Pease, R. S. The displacement of atoms in solids by radiation. Rep. Prog. Phys. 18 (1955)

25. Frenkel, J. On pre-breakdown phenomena in insulators and electronic semi-conductors. Phys. Rev. 54, 647-648 (1938).

26. Norgett, M. I., Robinson, M. T. \& Torrens, I. M. A proposed method of calculating displacement dose rates. Nucl. Eng. Des. 33, 50-54 (1975).

27. ASTM E693 Standard Practice for Characterizing Neutron Exposures in Iron and Low Alloy Steels in Terms of Displacements Per Atom (DPA)

28. Odette, G. R. Modelling of microstructural evolution under irradiation. I. Nucl. Mater. 85-86, 533-545 (1979).

29. Zinkle, S. \& Moeslang, A. Evaluation of irradiation facility options for fusion materials research and development. Fusion Eng. Des. 88, 472-482 (2013).

30. Ehrlich, K., Bloom, E. E. \& Kondo, T. International strategy for fusion materials development. J. Nucl. Mater. 283-287, 79-88 (2000).

31. Zinkle, S. J. \& Snead, L. L. Designing radiation resistance in materials for fusion energy. Annu. Rev. Mater. Res. 44, 241-267 (2014).

32. Odette, G. R. \& Frey, D. Development of mechanical property correlation methodology for fusion environments. J. Nucl. Mater. 85-86, 617-822 (1979).
33. Kiritani, M. Fission-fusion correlation by fission reactor irradiation with improved control. J. Nucl. Mater. 174, 327-351 (1990).

34. Was, G. S. Materials degradation in fission reactors: lessons learned of relevance to fusion reactor systems. J. Nucl. Mater. 367-370, 11-20 (2007).

35. Kiritani, M. The need for improved temperature control during reactor irradiation. J. Nucl. Mater. 160, 135-141 (1988).

36. Moeslang, A., Adelhelm, C. \& Heidinger, R. Innovative materials for energy technology. Int. J. Mater. Res. 99, 10 (2008).

37. Zinkle, S. Fusion materials science: overview of challenges and recent progress. Phys. Plasmas 12, 058101 (2005).

38. Wong, C. P. C. et al. Overview of liquid metal TBM concepts and programs. Fusion Eng. Des. 83, 850-857 (2008).

39. Tavassoli, A. et al. Current status and recent research achievements in ferritic/martensitic steels. J. Nucl. Mater. 455, 296-276 (2014).

40. Wurster, S. et al. Recent progress in R\&D on tungsten alloys for divertor structural and plasma facing materials. J. Nucl. Mater. 442, S181-S189 (2013).

41. Knitter, R. Recent developments of solid breeder fabrication. J. Nucl. Mater. 442, S420-S424 (2013).

42. Weber, H. Radiation effects on superconducting fusion magnet components. Int. J. Mod. Phys. E 20, 1325-1378 (2011)

43. Humer, K. et al. Characterization and qualification of advanced insulators for fusion magnets. Fusion Eng. Des. 88, 350-360 (2013).

44. Heidinger, R., Rohde, M. \& Spörl, R. Neutron irradiation studies on window materials for EC wave system. Fusion Eng. Des. 56-57, 471 (2001).

45. Wirth, B. D. et al. Modelling defect cluster evolution in irradiated structura materials: focus on comparing to high-resolution experimental characterization studies. J. Mater. Res. 30 (2015).

46. Wirth, B. D. et al. Fusion materials modelling: challenges and opportunities Mater. Res. Soc. 36 (2011).

47. Crocombette, J.-P. \& Willaime, F. Comprehensive Nuclear Materials Vol. 1 Ch. 8 (Elsevier, 2012)

48. Marinica, M.-C. et al. Irradiation-induced formation of nanocrystallites with C15 laves phase structure in bcc iron. Phys. Rev. Lett. 108, 025501 (2012).

49. Bachurin, D. V. et al. Ab initio study of hydrogen on beryllium surfaces. Surf. Sci. 641, 198-203 (2015).

50. Nguyen-Manh, D. \& Dudarev, S. L. Trapping of He clusters by inert-gas impurities in tungsten: first-principles predictions and experimental validation. Nucl. Instrum. Methods Phys. Res. B 352, 86-91 (2015).

51. Cai, W., Li, J. \& Yip, S. Comprehensive Nuclear Materials Vol. 1 Ch. 9 (Elsevier 2012).

52. Sand, A. E. et al. High-energy collision cascades in tungsten: dislocation loops structure and clustering scaling laws. Europhys. Lett. 103, 46003 (2013)

53. Stoller, R. E. The role of cascade energy and temperature in primary defect formation in iron. J. Nucl. Mater. 276, 22-32 (2000)

54. Becquart, C. S. \& Wirth, B. D. Comprehensive Nuclear Materials Vol. 1 Ch. 14 (Elsevier, 2012).

55. Souidi, A. et al. On the correlation between primary damage and long-term nanostructural evolution in iron under irradiation. J. Nucl. Mater. 419 , $122-133$ (2011)

56. Ghoniem, N. M. Comprehensive Nuclear Materials Vol. 1 Ch. 16 (Elsevier 2012).

57. Arsenlis, A. et al. A dislocation dynamics study of the transition from homogeneous to heterogeneous deformation in irradiated body-centered cubic iron. Acta Mater. 60, 3748-3757 (2012).

58. Stoller, R. E. et al. Mean field rate theory and object kinetic Monte Carlo: a comparison of kinetic models. J. Nucl. Mater. 382, 77 (2008).

59. Besmann, T. M. Comprehensive Nuclear Materials Vol. 1 Ch. 17 (Elsevier, 2012).

60. Franke, P. \& Seifert, H. J. The influence of magnetic and chemical ordering on the phase diagram of $\mathrm{Cr}-\mathrm{Fe}-\mathrm{Ni}$. Calphad 35, 148-154 (2011)

61. Bellon, P. Comprehensive Nuclear Materials Vol. 1 Ch. 15 (Elsevier, 2012).

62. www.iter.org

63. Giancarli, L. et al. Test blanket modules in ITER: an overview on proposed designs and required DEMO-relevant materials. J. Nucl. Mater. 367-370, 1271-1280 (2007).

64. Ehrlich, K. et al. in 17th Int. Symp. Eff. Radiat. Mater. Vol. 1270 (eds Gelles, D. et al.) 1109-1112 (ASTM STP, 1996).

65. Gilbert, M. R. \& Forrest, R. A. Handbook of Handbook of Activation Data Calculated Using EASY-2003 Report UKAEA FUS 509, July 2004

66. Katoh, Y. et al. Current status and recent research achievements in $\mathrm{SiC} / \mathrm{SiC}$ composites. J. Nucl. Mater. 455, 387-397 (2014).

67. Muroga, T. Present status of vanadium alloys for fusion applications. J. Nucl. Mater. 455, 263-268 (2014).

68. El-Guebaly, L. et al. Blanket/materials testing strategy for FNSF and its breeding potential, TOFE 2014 proceedings. Fusion Sci. Technol. 68 (2014).

69. Odette, G. R. et al. Recent developments in irradiation-resistant steels. Annu. Rev. Mater. Res. 38, 471-503 (2008). 
70. Gilbert, M. R. et al. Neutron-induced dpa, transmutations, gas production, and helium embrittlement of fusion materials. J. Nucl. Mater. 442, S755-S760 (2013).

71. Odette, G. R. On the ductile to brittle transition in martensitic stainless steels-mechanisms, models and structural implications. J. Nucl. Mater. 212-215, 45-51 (1994)

72. Fletcher, R. C. \& Brown, W. L. Annealing of bombardment damage in a diamond-type lattice: theoretical. Phys. Rev. 92, 3 (1953)

73. Gaganidze, E. et al. Mechanical properties and TEM examination of RAFM steels irradiated up to 70 dpa in BOR-60. J. Nucl. Mater. 417, 93-98 (2011).

74. Materna-Morris, E. et al. Effect of helium on tensile properties and microstructure in $9 \% \mathrm{Cr}-\mathrm{WVTa}$-steel after neutron irradiation up to $15 \mathrm{dpa}$ between 250 and $450{ }^{\circ}$ C. J. Nucl. Mater. 386-388, 422-425 (2009).

75. Stork, D. Developing structural, high-heat flux and plasma facing materials for a near-term DEMO fusion power plant: the EU assessment. J. Nucl. Mater. 455, 277-291 (2014).

76. Knaster, J. et al. IFMIF, a fusion relevant neutron source for material irradiation current status. J. Nucl. Mater. 453, 115-119 (2014).

77. Vladimirov, P. \& Möslang, A. Comparison of material irradiation conditions for fusion, spallation, stripping and fission neutron sources. J. Nucl. Mater. 343, 205-211 (2005).

78. Grand, P. et al. An intense $\mathrm{Li}(\mathrm{d}, \mathrm{n})$ neutron radiation test facility for controlled thermonuclear reactor materials testing. Nucl. Technol. 29, 327 (1976).

79. Torego, A. L. et al. Fusion materials irradiation test facility-a facility for fusion materials qualification. Nucl. Technol./Fusion 4, 695 (1983).

80. Surrey, E. et al. FAFNIR: strategy and risk reduction in accelerator driven neutron sources for fusion materials irradiation data. Fusion Eng. Des. 89, 2108-2113 (2014)

81. Yamanishi, T. et al. Recent technical progress on BA Program: DEMO activities and IFMIF/EVEDA. Fusion Eng. Des. (2016)

82. Abdou, M. A. A volumetric neutron source for fusion nuclear technology testing and development. Fusion Eng. Des. 27, 111-153 (1995).

83. Vos, G. M. et al. Conceptual design of a component test facility based on the spherical tokamak. Fusion Eng. Des. 83, 1648-1653 (2008).

84. Peng, Y. K. M. et al. Fusion Nuclear Science Facility (FNSF) before upgrade to Component Test Facility (CTF). Fusion Sci. Technol. 60 (2011).

85. Gilbert, M. R. \& Sublet, J.-Ch. Neutron-induced transmutation effects in W and W-alloys in a fusion environment. Nucl. Fusion 51, 043005 (2011).

86. Li, M. et al. Sweeping heat flux loads on divertor targets: thermal benefits and structural impacts. Fusion Eng. Des. 102, 50-58 (2016).

87. Pintsuk, G. Comprehensive Nuclear Materials Vol. 4 Ch. 17 (Elsevier, 2012)

88. Snead, L. \& Ferraris, M. Comprehensive Nuclear Materials Vol. 4 Ch. 18 (Elsevier, 2012).

89. Federici, G. et al. Comprehensive Nuclear Materials Vol. 4 Ch. 19 (Elsevier, 2012)

90. Smid, I. et al. Development of tungsten armor and bonding to copper for plasma-interactive components. J. Nucl. Mater. 258-263, 160-172 (1998).

91. Rieth, M. et al. Recent progress in research on tungsten materials for nuclear fusion applications in Europe. J. Nucl. Mater. 432, 482-500 (2013).

92. Leonard, K. J. Comprehensive Nuclear Materials Vol. 4 Ch. 6 (Elsevier, 2012).

93. Stork, D. et al. Materials R\&D for a timely DEMO: key findings and recommendations of the EU Roadmap Materials Assessment Group. Fusion Eng. Des. 89, 1586-1594 (2014).

94. Roedig, M. et al. Investigation of tungsten alloys as plasma facing materials for the ITER divertor. Fusion Eng. Des. 61-62, 135-140 (2002).

95. Shimakawa, S. et al. New electron beam facility for irradiated plasma facing materials testing in hot cell. J. Nucl. Mater. 233-237, 1582-1585 (1996).

96. Duwe, R. et al. Proc. 18th Symp. Fusion Technol. (SOFT)355-358 (1994).

97. Akiba, M. et al. Performance of JAERI electron beam irradiation stand. Plasma Dev. Oper. 1, 205-212 (1991).

98. Tokunaga, K. et al. High-heat-flux experiment on plasma-facing materials by electron beam irradiation. J. Nucl. Mater. 212-215, 1323-1328 (1994).

99. Diotalevi, M. et al. Proc. 19th Symp. Fusion Technol. (SOFT) (1996).

100. Wu, J. H. et al. Research of high heat flux for divertor materials. Chin. J. Nucl. Sci. Eng. 23, 132 (2003)

101. Gervash, A. et al. Comparative thermal cyclic testing and strength investigation of different $\mathrm{Be} / \mathrm{Cu}$ joints. Fusion Eng. Des. 39-40, 543-549 (1998).

102. Youchison, D. L., McDonald, J. M. \& Wold, L. S. Heat Transfer in High Heat Flux Systems Book No. G00956 (eds Boyd, R. D. \& Ghajar, A. J.) (ASME, 1994).

103. Hofmann, G. \& Eggert, E. First wall test facility FIWATKA, KfK 5381, (1994)

104. Dell'Orco, G. et al. Thermal-mechanical test on ITER primary first wall mock-ups. Fusion Eng. Des. 61-62, 117-122 (2002).

105. Hirai, T., Ezato, K. \& Majerus, P. ITER relevant high heat flux testing on plasma facing surfaces. Mater. Trans. 46, 412-424 (2005).
106. Bucalossi, J. et al. The WEST project: testing ITER divertor high heat flux component technology in a steady state tokamak environment. Fusion Eng. Des. 89, 907-912 (2014).

107. Bloom, E. E. et al. in Proc. 3rd Topical Meeting Technol. Control. Nucl. Fusion CONF-780808 (eds Powell, J. R. \& Eterno, C. T.) 554-564 (NTIS, 1978).

108. Bloom, E. E. et al. Low activation materials for fusion applications. J. Nucl. Mater. 122, 123, 17-26 (1984)

109. Ullmaier, H. The influence of helium on the bulk properties of fusion reactor structural materials. Nucl. Fusion 24, 1039-1083 (1984).

110. Harries, D. R. et al. Evaluation of reduced-activation options for fusion materials development. J. Nucl. Mater. 191-194, 92-99 (1992).

111. Baluc, N. et al. Status of R\&D activities on materials for fusion power reactors Nucl. Fusion 47, S696-S717 (2007).

112. Bloom, E. E. et al. Critical questions in materials science and engineering for successful development of fusion power. J. Nucl. Mater. 367-370, 1-10 (2007).

113. Zinkle, S. J., Möslang, A., Muroga, T. \& Tanigawa, H. Multimodal options for materials research to advance the basis for fusion energy in the ITER era. Nucl. Fusion 53, 104024 (2013).

114. Knaster, J. et al. Assessment of the beam-target interaction of IFMIF: a state of the art. Fusion Eng. Des. 89, 1709-1716 (2014).

115. Knaster, J. et al. IFMIF: overview of the validation activities. Nucl. Fusion 53, 116001 (2013).

116. Micciche, G. et al. IEEE 25th Symp. Fusion Eng. (SOFE) (2013)

117. Fischer, U. et al. Overview of recent progress in IFMIF neutronics. Fusion Eng. Des. 81, 1195-1202 (2006).

118. Knaster, J. et al. The accomplishment of the Engineering Design Activities of IFMIF/EVEDA: the European-Japanese project towards a Li(d,xn) fusion relevant neutron source. Nucl. Fusion 086003 (2015).

119. Arbeiter, F. et al. Design description and validation results for the IFMIF High Flux Test Module as outcome of the EVEDA phase. Nucl. Mater. Energy (2016)

120. Kondo, H. et al. Validation of IFMIF liquid Li target for IFMIF/EVEDA project. Fusion Eng. Des. 96-97, 117-122 (2015).

121. Kondo, H. et al. Demonstration of Li target facility in IFMIF/EVEDA project: Li target stability in continuous operation of entire system. Fusion Eng. Des. (2015).

122. Kanemura, T. et al. Measurement of Li target thickness in the EVEDA Li test loop. Fusion Eng. Des. 98-99, 1991-1997 (2015).

123. Knaster, J. et al. IFMIF, the European-Japanese efforts under the broader approach agreement towards a $\operatorname{Li}(\mathrm{d}, \mathrm{xn})$ neutron source: current status and future options. Nucl. Mater. Energy (2016).

124. Perez, M. et al. The engineering design evolution of IFMIF: from CDR to EDA. Fusion Eng. Des. (2015)

125. Pottmeyer, E. W. Jr The fusion material irradiation facility at Handford. $J$. Nucl. Mater. 85, 86, 463-465 (1979).

126. Noda, K. et al. Present status of ESNIT (energy selective neutron irradiation test facility) program. J. Nucl. Mater. 212-215, 1649-1654 (1994).

127. Knaster, J. \& Okumura, Y. Accelerators for fusion materials testing. Rev. Accel. Sci. Technol. 8 (2016).

128. Young, L. M. et al. Proc. LINAC 2000 Monterey.

129. Taylor, T. \& Wills, J. S. C. A high-current low-emittance dc ECR proton source. Nucl. Instrum. Methods Phys. Res. A 309, 37-42 (1991).

130. Shepard, K. W. et al. Proc. PAC 1999.

131. Kelly, M. Superconducting radio-frequency cavities for low-beta particle accelerators. Rev. Accel. Sci. Technol. 5, 185 (2012).

132. Cara, P. et al. Proc. IPAC 2016, http://www.jacow.org

133. Okumura, Y. et al. Operation and commissioning of IFMIF (International Fusion Materials Irradiation Facility) LIPAc Injector. Rev. Sci. Inst. (2016).

134. Kondo, H. et al. IFMIF/EVEDA lithium test loop: design and fabrication technology of target assembly as a key component. Nucl. Fusion 51, 123008 (2011).

135. Arbeiter, F. et al. Development and validation status of the IFMIF High Flux Test Module. Fusion Eng. Des. 86, 607-610 (2011).

136. Schlindwein, G. et al. Start-up phase of the HELOKA-LP low pressure helium test facility for IFMIF irradiation modules. Fusion Eng. Des. 87, 737-741 (2012).

137. Lucas, G. E. The development of small specimens mechanical test techniques. J. Nucl. Mater. 117, 327-339 (1983).

138. Jung, P. et al. Recommendation of miniaturized techniques for mechanical testing of fusion materials in an intense neutron source. J. Nucl. Mater. 232, 186-205 (1996)

139. Lucas, G. E. et al. The role of small specimen test technology in fusion materials development. J. Nucl. Mater. 367-370, 1549-1556 (2007)

140. Wakai, E. et al. Overview on recent progress towards small specimen test technique. Fusion Eng. Des. (2015). 
141. Nogami, S. et al. Development of fatigue life evaluation method using small specimen. J. Nucl. Mater. 441, 125-132 (2013).

142. Kim, B. J. et al. Application of master curve method to the evaluation of fracture toughness of F82H steels. J. Nucl. Mater. 442, S38-S42 (2013).

143. Ito, Y. et al. Crack growth behavior of $\mathrm{F} 82 \mathrm{H}$ steel in the $288^{\circ} \mathrm{C}$ water. J. Plasma Fusion Res. 11 (2015).

144. Ibarra, A. et al. A stepped Approach from IFMIF/EVEDA toward IFMIF. Fusion Sci. Tech. 66 (2014).

145. Heidinger, R. et al. Technical analysis of an early fusion neutron source based on the enhancement of the IFMIF/EVEDA accelerator prototype. Fusion Eng. Des. 89, 2136-2140 (2014).
146. Mota, F. et al. Sensitivity of IFMIF-DONES irradiation characteristics to different design parameters. Nucl. Fusion 55, 123024 (2015).

\section{Additional information}

Reprints and permissions information is available online at www.nature.com/reprints. Correspondence should be addressed to J.K.

\section{Competing financial interests}

The authors declare no competing financial interests. 